\title{
Application of in vitro pollination of opened ovaries to obtain Brassica oleracea L. $\times$ B. rapa L. hybrids
}

\author{
Katarzyna Sosnowska • Teresa Cegielska-Taras
}

Received: 24 May 2013 / Accepted: 25 November 2013 /Published online: 12 December 2013 / Editor: J. Forster

(C) Society for In Vitro Biology 2013

\begin{abstract}
This study presents the results of experiments concerning: (1) interspecific hybridization of Brassica oleracea $\times$ Brassica rapa via application of in vitro placental pollination and (2) embryological analysis of the process of resynthesis of Brassica napus. In order to overcome certain stigma/style barriers, B. rapa pollen was placed in vitro on an opened B. oleracea ovary (with style removed). Pollinated ovaries were cultured on Murashige and Skoog (MS) medium. After 24-d culture, the developing embryos were isolated from immature seeds and transferred onto MS medium supplemented with $0.47 \mu \mathrm{M}$ kinetin, $0.49 \mu \mathrm{M}$ 1-naphthaleneacetic acid, and $10 \%(v / v)$ coconut water. When the embryos had turned green, they were immediately placed onto MS medium with $100 \mu \mathrm{M}$ kinetin. After development of the seedling, plantlets were transferred to soil. Chromosome doubling was achieved after another week. Cytometric analysis of nuclear DNA confirmed the hybrid nature of the plants. Resynthesis of $B$. napus can be performed through interspecific hybridization of $B$. oleracea $\times$ B. rapa followed by embryo rescue and genome doubling.
\end{abstract}

Keywords In vitro pollination $\cdot$ Brassica oleracea $\cdot$ Brassica rapa $\cdot$ Interspecific hybridization

\section{Introduction}

Currently, increasing the genetic diversity of plants by using in vitro culture techniques is a significant challenge in plant breeding programs. Oilseed rape (Brassica napus L., AACC,

K. Sosnowska $(\bowtie) \cdot$ T. Cegielska-Taras Department of Genetics and Breeding of Oilseed Crops, Plant Breeding and Acclimatization Institute - National Research Institute, Strzeszynska 36, 60-479 Poznan, Poland

e-mail: sosnowska@tlen.pl
$2 n=38$ ) evolved as a natural amphidiploid following spontaneous hybridization between two diploid species (U N 1935), i.e., turnip rape (Brassica rapa L., AA, $2 n=20$ ) and curly kale (Brassica oleracea L., CC, $2 n=18$ ). The limited geographical restriction of oilseed rape cultivation, combined with intensive quality breeding (double-low varieties), led to significant limits in the genetic pool of this species. Due to the large number of closely related species of the genus Brassica, it is possible to transfer, via distant crossing, new features which are beneficial for oilseed rape breeding material (in terms of improvements in seed yield, disease, and pest resistance, as well as seed quality traits). One way to broaden the range of genetic variation accessible to breeders is to obtain resynthetic (RS) oilseed rape via interspecific crossing between two basic species: B. oleracea and B. rapa (Rahman 2013).

Resynthesis of $B$. napus has been performed with good results through in vivo crossing of $B$. rapa $\times$ B. oleracea, and then hybrid plants have been obtained through embryo rescue culture (Sosnowska et al. 2010). While B. oleracea has been chosen as the maternal parent for crossing with $B$. rapa, sometimes it has been problematic (Lu et al. 2001).

In hybridization between distant species, incompatibility barriers (pre- and postzygotic obstacles) often prevent interspecific crosses. In prezygotic barriers, pollen tubes may start to grow, but then they do not reach the ovules due to the presence of incompatibility mechanisms operating in the stylar tissue. Furthermore, postzygotic barriers may lead to a restriction of embryo growth and development, due to a lack of endosperm development (Zenkteler 1990).

Direct in vitro pollination of stigma or pistils and opened ovaries or ovules may be useful in overcoming incompatibility barriers (Zenkteler 1991, 2000). The best results have been achieved in species with large ovaries containing many ovules, such as those belonging to Brassicaceae, Caryophyllaceae, Papaveraceae, Primulaceae, and Solanaceae families (Rangaswamy 1977; Zenkteler 1999). For example, Kameya 
and Hinata (1970) used ovule pollination to obtain hybrids between Brassica chinensis and Brassica pekiniensis.

Successful application of this method largely depends on the age of the embryo being rescued and cultured in vitro. Hybrid plants have been relatively easily developed from embryos at the autotrophic phase of growth, which begins at the heart stage (Zenkteler 1990).

The aim of this study was to elaborate a method for the interspecific crossing of $B$. oleracea $\times B$. rapa through in vitro pollination of the opened ovary and thus obtain a new genotype (resynthesis) of B. napus.

\section{Materials and Methods}

Plant material. In the experiment on the interspecific cross, B. oleracea L. ssp. acephala var. sabellica (curly kale) cv. 'Vitessa' was used as the female parent, while B. rapa L. ssp. rapifera (turnip rape), spring type cvs. 'Kova' and 'Skye' and winter type cvs. 'Credit', 'Ludowy', and 'Premium' were selected as pollen donors. Parental plants were grown in growth cabinets. Closed flower buds were harvested from curly kale about $48 \mathrm{~h}$ before opening. These flower buds were surface-sterilized (in a laminar air-flow cabinet) for $20 \mathrm{~s}$ in $70 \%(v / v)$ ethanol followed by $3 \mathrm{~min}$ in chlorine water and rinsed two times in sterile water.

Embryo rescue. For in vitro culture conditions, the petals and some sepals were removed and the stigma was cut off jointly with the style, and the upper part of the ovary was cut open to expose the ovules. Pollen grains from the anthers of flowers (of turnip rape) were placed directly on the surface of the exposed ovules (curly kale). These pollinated ovaries were transferred to culture medium in glass tubes $(30 \mathrm{~mL}$ capacity containing $6 \mathrm{~mL}$ culture medium; four to five ovaries placed per glass tube). Tubes were plugged with cotton wool. Murashige and Skoog (MS) medium (Murashige and Skoog 1962) was supplemented with $2 \%(w / v)$ sucrose and the $\mathrm{pH}$ was adjusted to 5.6 before autoclaving. Explants were incubated at $20-22^{\circ} \mathrm{C}$ over a $16-\mathrm{h}$ photoperiod.

Enlarged ovules were isolated from the ovary $14 \mathrm{~d}$ after in vitro pollination and transferred to MS medium supplemented with $0.47 \mu \mathrm{M}$ kinetin and $0.49 \mu \mathrm{M} 1$-naphthaleneacetic acid (NAA), $10 \%(v / v)$ coconut water, and $2 \%(w / v)$ sucrose. Then, after a further $10 \mathrm{~d}$, embryos from the enlarged ovules were dissected and transferred to the same, fresh medium. When the explants had turned green, they were transferred to MS medium with $100 \mu \mathrm{M}$ kinetin. The shoots were rooted on MS medium with $49.2 \mu \mathrm{M}$ indole-3-butyric acid (IBA) (Cegielska-Taras et al. 2002). Plantlets were transferred to soil.

Cytometric analysis. Young leaf tissue $\left(\sim 1 \mathrm{~cm}^{2}\right)$ was harvested from plants growing in the growth cabinets and used for flow cytometry. Samples were prepared according to Galbraith et al. (1983) with some modifications. Plant tissue was chopped with razor blade in a Petri dish, containing $2 \mathrm{~mL}$ lysis buffer, with addition of $5.71 \mu \mathrm{M} \mathrm{4}$ ',6-diamidino-2-phenylindole and $15 \times 10^{3} \mu \mathrm{M} \beta$-mercaptoethanol. Suspensions were passed through a nylon filter with $30-\mu \mathrm{m}$ mesh size and the analyses were performed using PAII (Partec, Germany) flow cytometer. For each leaf sample, 5,000-8,000 nuclei were analyzed with five replications, using a logarithmic scale. Histograms were analyzed with the use of a DPAC v. 2.2 software (Partec Gmbh, Germany).

Chromosome doubling. Plants at the four- to six-leaf stages were vernalized at $4{ }^{\circ} \mathrm{C}$ for $7 \mathrm{wk}$. Subsequently, the number of chromosomes in the hybrid plants was doubled by dipping the roots in $0.05 \%(w / v)$ colchicine solution for $24 \mathrm{~h}$ and, after washing the roots, the plants were transferred back into soil. Further development of plant RS oilseed rape occurred in a greenhouse.

Embryological study. Pollen germination on the upper part of the ovary was observed under a fluorescent microscope using aniline blue $\left(0.1 \mathrm{~g} \mathrm{~L}^{-1} \mathrm{H}_{2} \mathrm{O}, \mathrm{pH}=7.2\right)$.

The enlarged ovaries and ovules were fixed in FAA $(5 \mathrm{~mL}$ $40 \%$ formalin $[v / v], 5 \mathrm{~mL}$ glacial acetic acid, and $90 \mathrm{~mL} 70 \%$ $[v / v]$ ethanol), passed through alcohol-xylene series (in a graded ethanol series from $70[v / v]$ to $100 \%[v / v], 1 \mathrm{~h}$ in each) and embedded in Paraplast ${ }^{\mathbb{B}}$. Sections were cut at a $10 \mu \mathrm{m}$ thickness and stained with Heidenhein's iron hematoxylin (Merck; $1.5 \mathrm{~g} \mathrm{~L}^{-1}$ of $80 \%[v / v]$ ethanol) and counterstained with Fast Green FCF (Merck) $\left(0.03 \mathrm{~g} \mathrm{~L}^{-1}\right.$ of clove oil). The material for embryological studies was fixed at various times after pollination. Embryogenesis was observed under a light microscope (Zeiss Axioscope A1, Jena, Germany) and micrographs were recorded using AxioVision software and a multimedia digital camera.

\section{Results}

B. oleracea L. ssp. acephala var. sabellica cv. 'Vitessa' and five varieties of spring and winter $B$. rapa L. ssp. rapifera were used in interspecific hybridization. During the study, 420 ovaries with exposed ovules were in vitro pollinated on MS medium. Several days after pollination (DAP), 217 enlarged ovules were observed. From these, 179 were prepared and cultured in vitro for further development, while the remaining 38 were fixed for embryological analysis.

Germination of pollen grains on ovules (exposed from the ovary) was observed after $24 \mathrm{~h}$ of culture (Fig. 1a). Pollen tubes had entered the embryo sac and were visible in many of the analyzed ovules $48 \mathrm{~h}$ after in vitro pollination (Fig. $1 b$ ). Embryological slides of ovaries $72 \mathrm{~h}$ after pollination showed 
Figure 1. In vitro pollination of ovaries. (a) Germination of pollen grains of $B$. rapa (arrows) on an opened ovary of $B$. oleracea, $24 \mathrm{~h}$ after pollination. (b) B. rapa pollen tube penetrating the $B$. oleracea embryo sac (arrow), $48 \mathrm{~h}$ after pollination. (c) Male B. rapa gamete enters the egg cell of $B$. oleracea (arrow). (d) Enlarged ovaries $B$. oleracea $\times B$. rapa, 5 DAP.
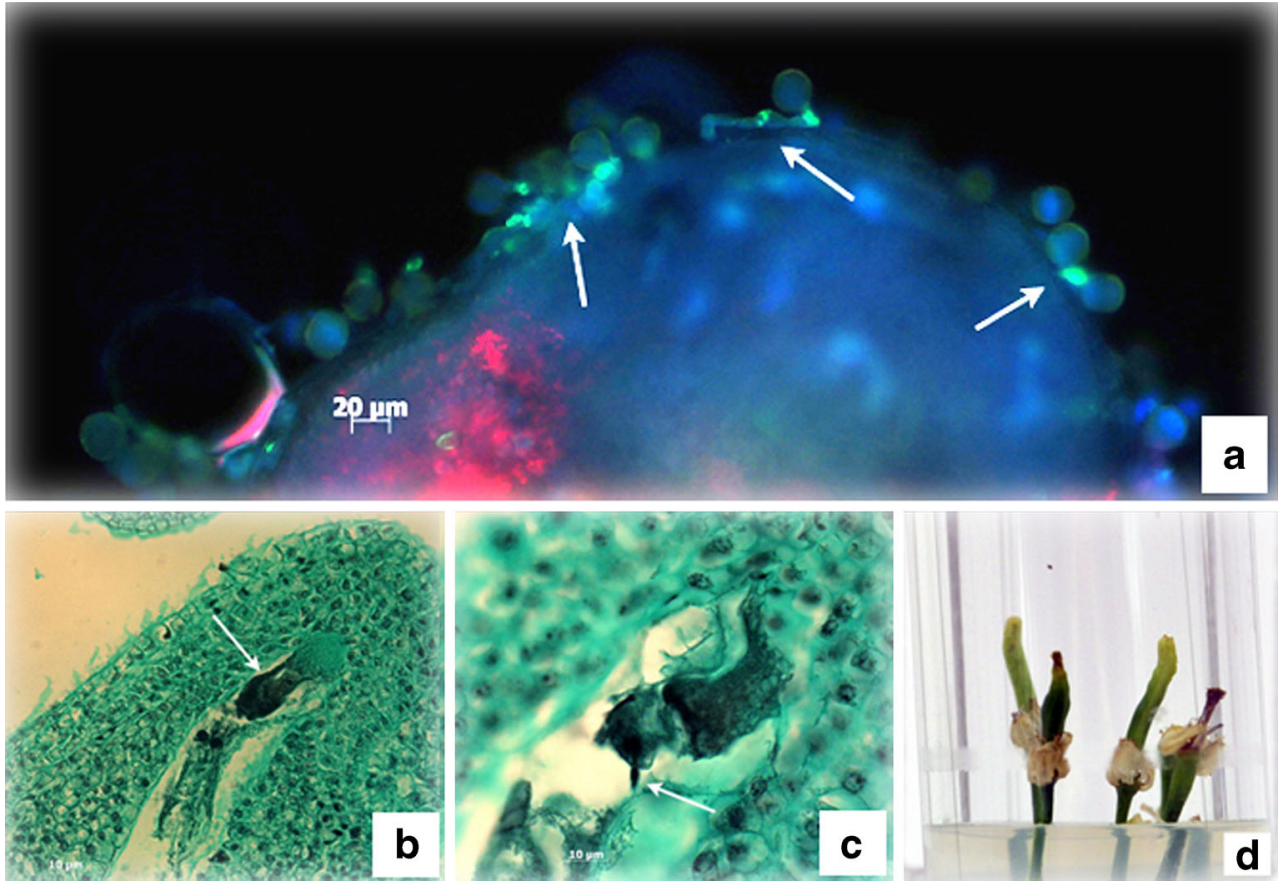

that male gametes had penetrated the egg cell of the embryo sacs (Fig. 1c), and $5 \mathrm{~d}$ after pollination some ovaries were enlarged (Fig. 1d).

Embryological analysis of ovules, 12-17 DAP, revealed the presence of embryos and endosperm at different stages of development (Fig. 2). Among enlarged ovules, some of them contained embryos with endosperm, some with embryos or endosperm only, and others had empty embryo sacs, as shown in Fig. 3. At 12 DAP, globular embryos of various sizes were observed, often with well-developed suspensors (Fig. 2a);
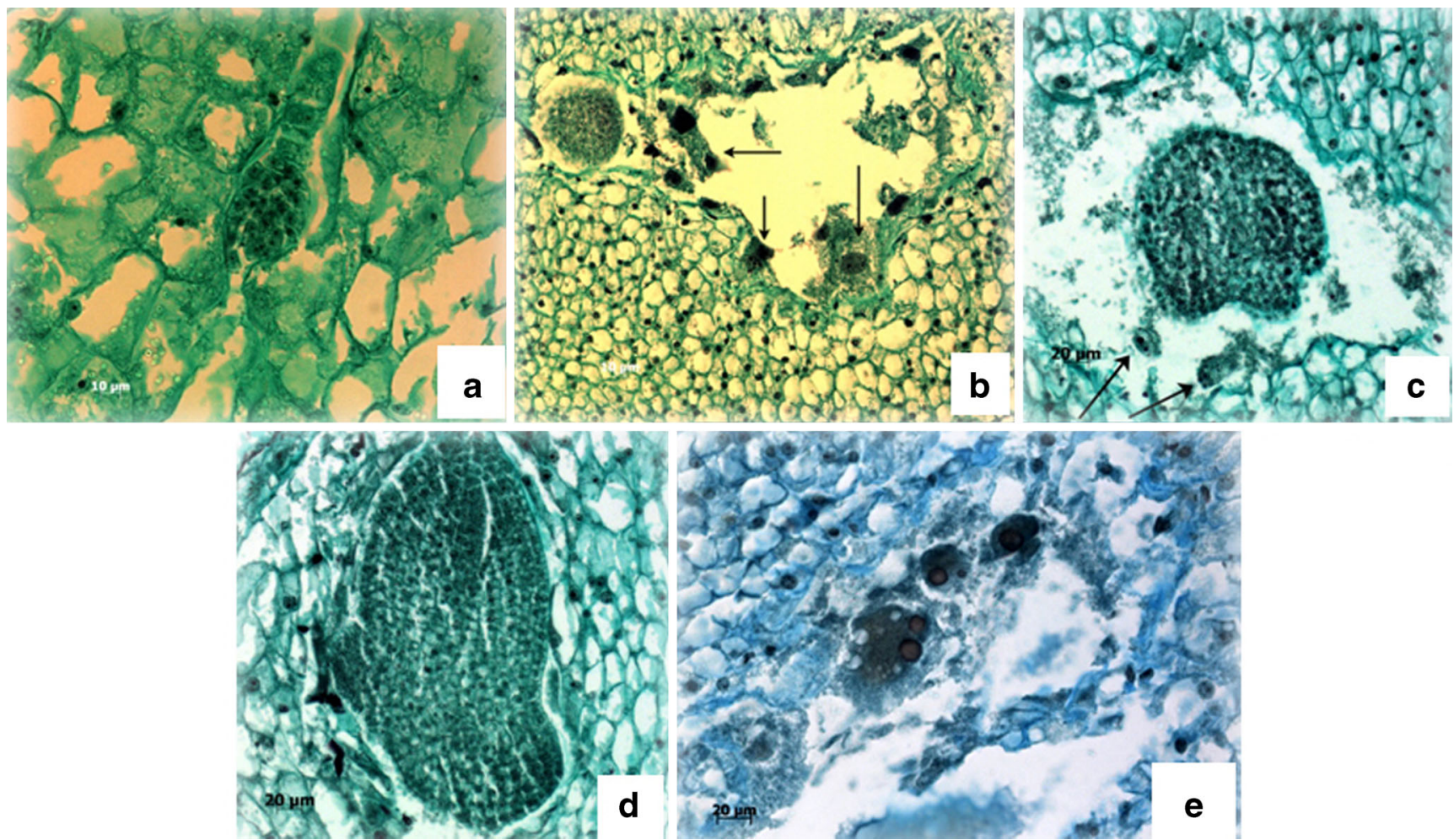

Figure 2. Embryological analysis of enlarged ovules. (a) Globular embryo with suspensor of $B$. oleracea $\times B$. rapa, endosperm absent, 12 DAP. $(b)$ Globular embryo of B. oleracea $\times$ B. rapa, hybrid endosperm (arrows), 14
DAP. (c) Heart stage embryo of $B$. oleracea $\times B$. rapa, residual endosperm (arrows), 15 DAP. (d) Torpedo stage embryo of B. oleracea $\times$ B. rapa, 17 DAP. (e) Hybrid, nuclear endosperm of $B$. oleracea $\times$ B. rapa, 13 DAP. 


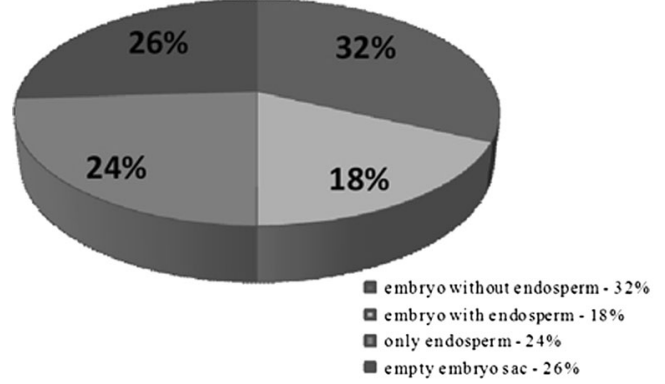

Figure 3. Embryological analysis of enlarged ovules, 12-17 DAP.

however, endosperm was often not present. Normally developed endosperm rarely occurred simultaneously with globular embryos 14 DAP (Fig. 2b). Endosperm was characterized by various numbers, sizes, and shapes of nuclei and multinucleoli.

Fifteen to $17 \mathrm{~d}$ after pollination, early heart- (Fig. $2 c$ ) and early torpedo-stage embryos (Fig. $2 d$ ) were identified as well. In some of the enlarged ovules, embryos were not present; however, nuclear endosperm was visible (Fig. 2e).

Embryological observations of in vitro pollinated ovules and the development of hybrid embryos allowed a determination of the time at which young embryos must be transferred to medium, due to the failure of endosperm to support further embryo development. Fourteen days after pollination, enlarged ovules (Fig. 4a) were isolated and transferred onto MS medium supplemented with NAA, kinetin, and coconut water. After a further $10 \mathrm{~d}$ of culture, mature embryos were dissected from the ovules and were also cultured on the same, but fresh medium (Fig. 4b). After several weeks, the resultant explants were transferred onto MS medium with $2 \%(w / v)$ sucrose, with the addition of kinetin and IBA, in order to foster the development of shoots and roots (Fig. 4c). Afterwards, plantlets were transferred to soil (Fig. $4 d$ ) and after vernalization, hybrid plants were grown in a greenhouse (Fig. 4e).

The numbers of pollinated ovaries, enlarged ovules, and resultant hybrid plants in different combinations of crosses are presented in Table 1. After in vitro pollination of 420 curly kale ovaries with pollen from turnip rape, 179 enlarged ovules were isolated, and 24 plants were recovered. Plants obtained from interspecific crossing were also examined for nuclear DNA content via flow cytometry. Analysis of leaf samples of received putative hybrids showed that they were amphihaploid $(n=19)$ as expected (Fig. 5). These plants were treated with colchicine in order to obtain amphidiploid $B$. napus plants $(2 n=38)$.

The average efficiency of obtaining new oilseed rape plants from enlarged ovules of curly kale crossed with different spring and winter varieties of turnip rape was around $13.4 \%$. With regard to the resultant hybrid plants, there was a negligible difference between the spring and winter type of turnip rape in the crosses performed.

\section{Discussion}

There are certain interspecific hybrids of $B$. oleracea and $B$. rapa that are very difficult to obtain via conventional sexual crossing (Chen and Heneen 1989; Lu et al. 2001). Such
Figure 4. Embryo rescue and plant regeneration. (a) Enlarged ovule inside an opened ovary, 14 DAP. (b) Mature $B$. oleracea $\times B$. rapa embryos germinating on medium. (c) Fully formed seedlings with roots. $(d)$ Hybrid plants of $B$. oleracea $\times$ B. rapa . (e) Flowering hybrid plant after vernalization.
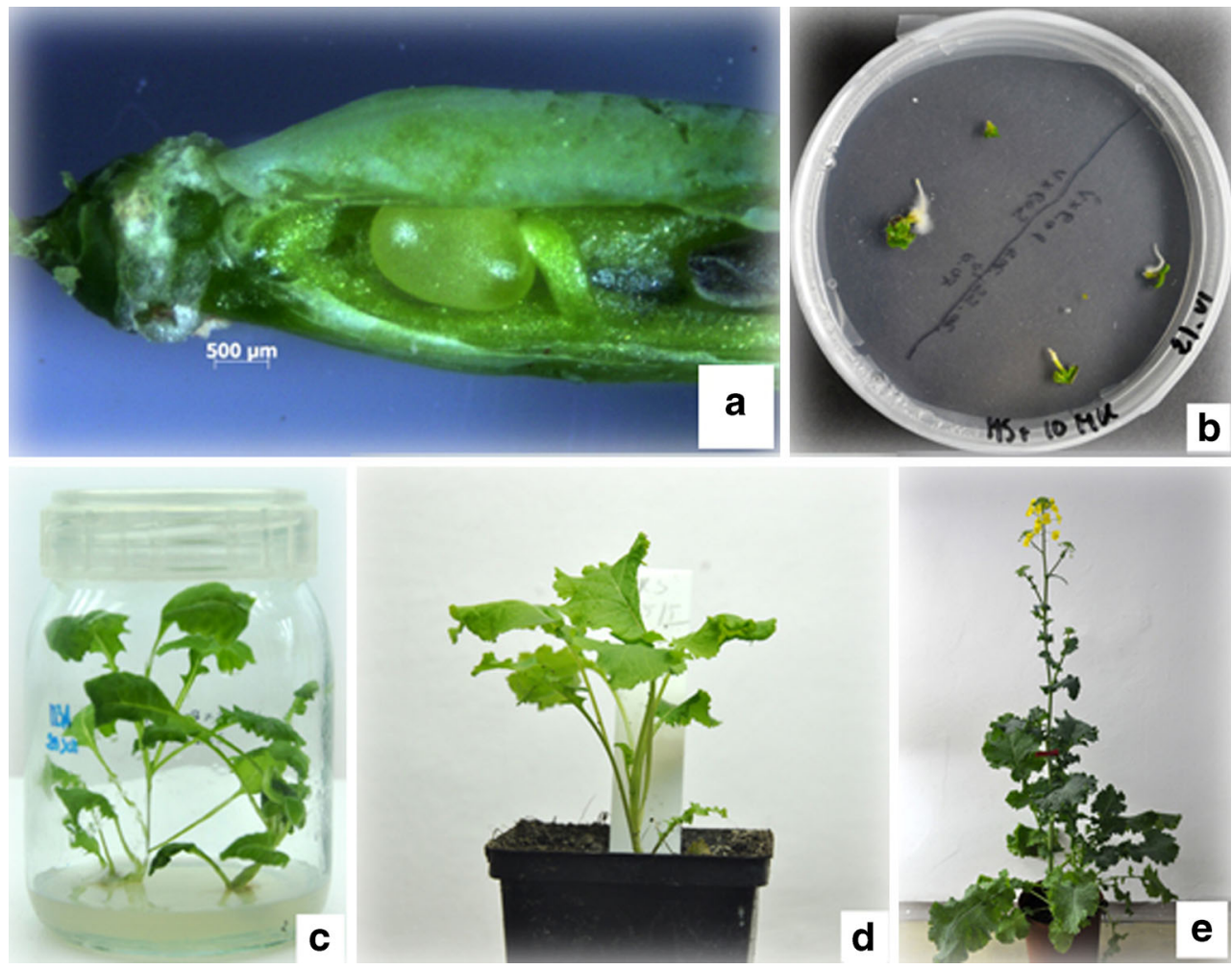
Table 1. Results of interspecific crossing between B. oleracea and B. rapa via in vitro pollination

\begin{tabular}{|c|c|c|c|c|}
\hline Cross B. oleracea $\times$ B. rapa & $\begin{array}{l}\text { No. of } \\
\text { pollinated } \\
\text { ovaries }\end{array}$ & $\begin{array}{l}\text { No. of } \\
\text { enlarged } \\
\text { ovules (A) }\end{array}$ & $\begin{array}{l}\text { No. of } \\
\text { hybrid } \\
\text { plants (B) }\end{array}$ & $\begin{array}{l}\text { Ratio } \\
\text { (B:A) }\end{array}$ \\
\hline Curly kale cv. 'Vitessa' × turnip rape cv. 'Kova'a & 70 & 19 & 3 & 0.158 \\
\hline Curly kale cv. 'Vitessa' $\times$ turnip rape cv. 'Skye'a & 48 & 15 & 5 & 0.333 \\
\hline Curly kale cv. 'Vitessa' $\times$ turnip rape cv. 'Credit' & 64 & 19 & 2 & 0.105 \\
\hline Curly kale cv. 'Vitessa' × turnip rape cv. 'Ludowy' & 151 & 59 & 5 & 0.085 \\
\hline Curly kale cv. 'Vitessa' × turnip rape cv. 'Premium' & 87 & 67 & 9 & 0.134 \\
\hline Total & 420 & 179 & 24 & 0.134 \\
\hline
\end{tabular}

${ }^{\text {a }}$ Spring variety

interspecific hybrids, however, can be obtained by in vitro or in vivo pollination in conjunction with embryo rescue.

Experiments involving crossing two genetically distant parental species can be very difficult or, in many cases, impossible. It is easier to produce progeny when species with a similar gene pool are crossed. Olsson (1960) observed that crosses within the genus Brassica occur most frequently when the maternal parent had a greater number of chromosomes than the paternal one. However, Takeshita et al. (1980) showed that when $B$. oleracea was used as a "mother", interspecific hybrids were much easier to obtain through the in vitro culture of embryos. B. oleracea, as a cytoplasmic donor, may also be a novel genetic resource for genes corresponding to quality and other traits to be transferred to B. napus .

Prezygotic incompatibility barriers between genetically distant species can be avoided or reduced by applying defined
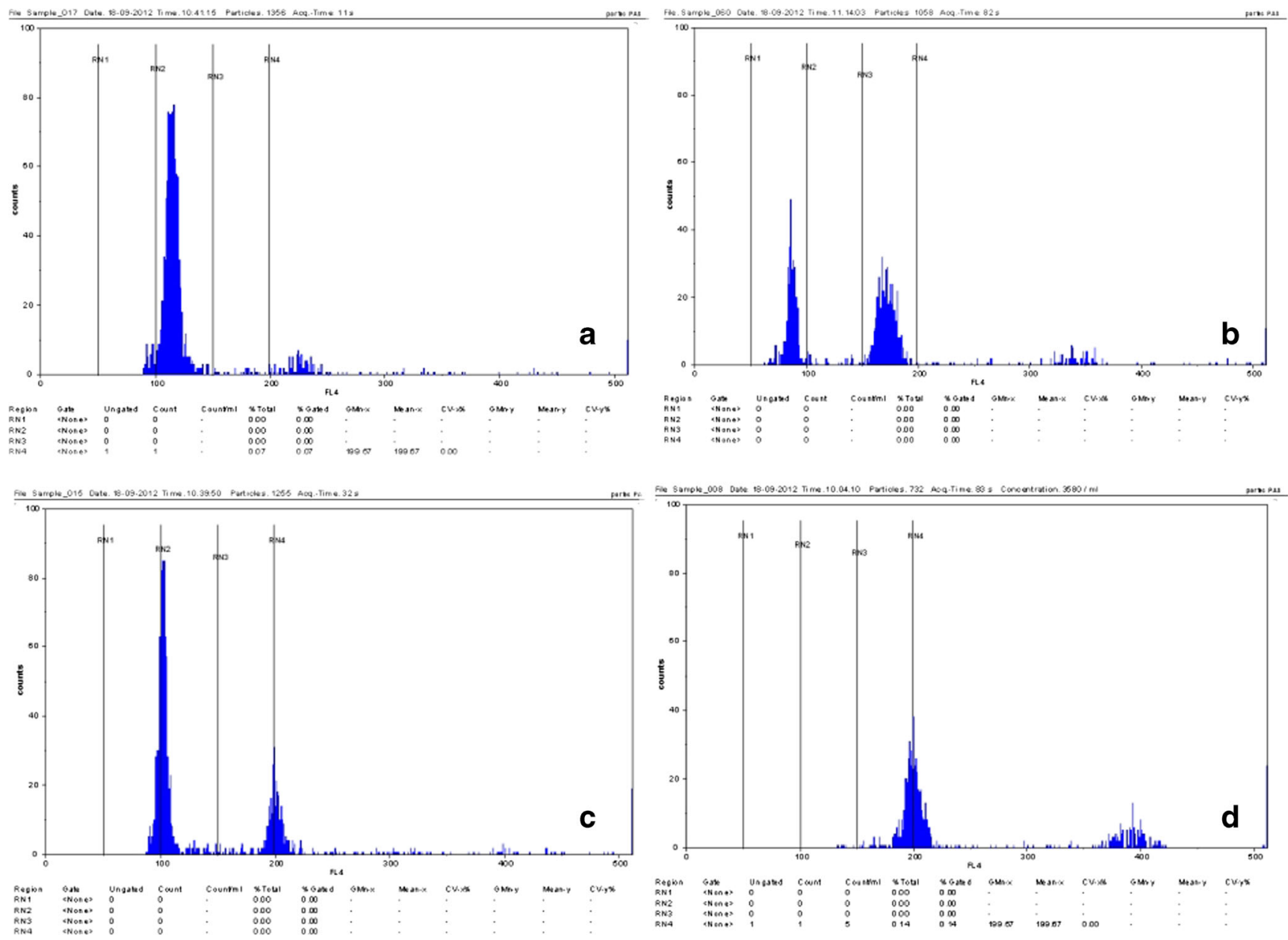

Figure 5. Histograms from flow cytometric analysis showing the ploidy status of $(a) B$. oleracea, $(b) B$. rapa, and $(c)$ resynthesized amphihaploid $B$. napus in comparison with $(d)$ normal amphidiploid B. napus cv. 'Monolit'. 
methods of pollination and in vitro culture, such as pollination of immature pistils, pollination of pistils with mixtures of compatible (inactivated by radiation or chemicals) and incompatible pollen, pollination of opened ovaries and placenta, or in vitro fertilization (Zenkteler et al. 1987; Tuyl and De Jeu 1997). Postzygotic incompatibility barriers, such as degeneration of embryos during embryogenesis, improper development of embryos (very often caused by abnormal development of the endosperm [Olsson 1960; Wojciechowski 1985]), can be also avoided by in vitro culturing of either isolated embryos or the maternal flower organs in order to induce further growth (Zenkteler 1990). By using these methods, regeneration of hybrid plants is possible. Species of the genus Brassica belong to those that employ a sporophytic incompatibility system, where pollen germination is blocked on the surface of the stigma (Zenkteler et al. 1987).

In the present study, in order to avoid the prezygotic barriers of crossing, opened ovaries (cut at the floral apex) were pollinated in vitro. Postzygotic barriers were overcome by in vitro culture of enlarged ovules with embryos, which were isolated 14 DAP (embryo rescue technique). After a further $10 \mathrm{~d}$, mature embryos were isolated and cultured. Finally, hybrid plants were obtained which were confirmed by cytometric analysis of DNA content. Flow cytometry is more convenient and rapid compared to the traditional karyotyping methods and the use of other morphological characteristics (e.g., size and number of leaf stomata), especially in the analysis of generated hybrid plants.

Application of these methods makes it possible to obtain $B$. napus hybrid plants from crosses between $B$. oleracea and $B$. rapa. Resynthesized $B$. napus is strategically important for the practical breeding of new oilseed rape to increase the gene pool for this crop.

Acknowledgments We would like to thank Professor Maciej Zenkteler for his critical reading of the manuscript and his useful comments. This work was partially supported by the Ministry of Agriculture and Rural Development, Poland, Project HOR hn 801 no 57.

\section{References}

Cegielska-Taras T.; Tykarska T.; Szała L.; Kuraś L.; Krzymański J. Direct plant development from microspore-derived embryos of winter oilseed rape Brassica napus L. ssp. oleifera (DC.) Metzger. Euphytica 124: 341-347; 2002.
Chen B.-Y.; Heneen W. Resynthesized Brassica napus L.: a review of its potential in breeding and genetic analysis. Hereditas 111: 255-263; 1989.

Galbraith D. W.; Harkins K. R.; Maddox J. M.; Ayres N. M.; Sharma D. P.; Firoozabady E. Rapid flow cytometric analysis of the cell cycle in intact plant tissues. Science 220: 1049$1051 ; 1983$.

Kameya T.; Hinata K. Test-tube fertilization of excised ovules in Brassica. Japan J Breed 20: 253-260; 1970.

Lu C. M.; Zhang B.; Kakihara F.; Kato M. Introgression of genes into cultivated Brassica napus through resynthesis of B. napus via ovule culture and the accompanying change in fatty acid composition. Plant Breed 120: 405-410; 2001.

Murashige T.; Skoog F. A revised medium for rapid growth and bioassays with tobacco tissue cultures. Physiol Plant 15: 473-497; 1962.

Olsson G. Species crosses within the genus Brassica. II. Artificial Brassica napus L. Hereditas 46: 351-386; 1960.

Rahman H. Review: breeding spring canola (Brassica napus L.) by the use of exotic germplasm. Can J Plant Sci 93: 1-11; 2013.

Rangaswamy N. S. Application of in vitro pollination and in vitro fertilization. In: Reinert J.; Bajaj Y. P. S. (eds) Applied and fundamental aspects of plant cell tissue, and organ culture. Springer, Berlin, pp 412-425; 1977.

Sosnowska K.; Szała L.; Olejnik A.; Cegielska-Taras T. Preliminary study on resynthesis of winter oilseed rape (Brassica napus L.). Oilseed Crops XXXI: 257-266; 2010.

Takeshita M.; Kato M.; Tokumasu S. Application of ovule culture to the production of intergeneric and interspecific hybrids in Brassica and Raphanus. Japan J Genet 55: 373-387; 1980.

Tuyl J. M.; De Jeu M. J. Methods for overcoming interspecific crossing barriers. In: Sawhney V. K.; Shivanna K. R. (eds) Pollen biotechnology for production and improvements. Cambridge University Press, Cambridge, UK, pp 273-292; 1997.

U N. Genome analysis in Brassica with special reference to the experimental formation of $B$. napus and peculiar mode of fertilization. Japan J Bot 7: 389-452; 1935.

Wojciechowski A. Interspecific hybrids between Brassica campestris L. and B. oleracea L. I. Effectiveness of crossing, pollen tube growth, embryogenesis. J Appl Genet 26: 423-436; 1985.

Zenkteler M. In vitro fertilization and wide hybridization in higher plants. CRC Crit Rev Plant Sci 9: 267-279; 1990.

Zenkteler M. Ovule culture and test tube fertilization. Med Fac Landbouww Rijksuniv Genet 56: 1403-1410; 1991.

Zenkteler M. In vitro pollination of excised ovaries. Acta Biol Cracov Bot 41: 31-38; 1999.

Zenkteler M. In vitro pollination of angiosperm ovules with gymnosperm pollen grains. In Vitro Cell Dev Biol-Plant 36: 125-127; 2000.

Zenkteler M.; Maheswaran G.; Williams E. G. In vitro placental pollination in Brassica campestris and B. napus. J Plant Physiol 128: 245 $250 ; 1987$. 